\title{
Influence of corrosion-related degradation of mechanical properties of shipbuilding steel on collapse strength of plates and stiffened panels
}

\author{
P. Jurišić \\ Croatian Register of Shipping, Split, Croatia \\ J. Parunov \\ Faculty of Mechanical Engineering and Naval Architecture, University of Zagreb, Zagreb, Croatia
}

\begin{abstract}
Statistics reveal that corrosion is the main cause of marine casualties in aged ships. Main adverse effect of corrosion is the reduction of the plate thickness leading to simultaneous increase of stresses and decrease of the structural capacity of ship structural components. It was recently found, however, that because of the complex interaction of various mechanical and chemical processes, mechanical properties, such as Young's modulus of elasticity and yield strength of corroded steel reduces with time. Such long-term degradation of mechanical properties may further reduce structural strength that is not adequately accounted for in ship structural design rules and structural safety analysis procedures. The aim of the present paper is to investigate the consequence of degradation of mechanical properties on collapse strength of plates and stiffened panels. Standard procedures from Common Structural Rules for collapse strength assessment are employed. Corrosion degradation which is required for assessment of loss of mechanical properties is estimated based on real thickness measurements of oil tankers. Conclusions about importance of this phenomenon are drawn.
\end{abstract}

\section{INTRODUCTION}

Damages to ships due to corrosion are very likely and the possibility of accident increases with the aging of ships. The consequences of corrosion wastage can be very serious in some circumstances so the experts in the maritime industry take into serious consideration corrosion wastage as one of the very important degradation factors for ship structural strength (Wang et al. 2009).

Main adverse effect of corrosion is the reduction of the plate thickness leading to simultaneous increase of stresses and decrease of the structural capacity of ship structural components (Guo et al. 2008). Therefore corrosion in ship structures has an important role in the long-term structural integrity.

Under unfavourable conditions, very high rates of corrosion can be achieved in ship structures. This has been a source of concern by ship operators and classification societies that have collected much service data (Wang et al. 2003). Different models have been proposed to explain the growth of corrosion wastage in ship structures combining the physics of corrosion growth with the fitting of service data (Garbatov et al. 2007).

It was recently found that because of the complex interaction of various mechanical and chemical processes, mechanical properties, such as
Young's modulus of elasticity and yield strength of corroded steel reduces with time (Garbatov et al. 2014). Chemical processes are e.g. hydrogen embrittlement phenomenon cause loss of ductility and strength. While mechanical defects that are manly caused by pits that are formed in addition to the uniform corrosion induce local stress concentrations that then may cause structural cracking.

These findings regarding loss of mechanical properties may influence significantly the strength assessment of corroded structures, as changes of material properties due to aging effects are normally ignored in the currently used procedures. This is the motivation of the present paper, i.e. to investigate the consequences of degradation of mechanical properties on collapse strength of plates and stiffened panels. Strength assessment is based on thickness gauges of aged oil tankers (Jurišić et al. 2011, 2014).

The paper is organized in following way. In the first section after introduction, description of ships and corrosion measurements is given. After that, description of mechanical properties degradation equations is given. Collapse strength assessment is then described according to the procedures proposed in Common Structural Rules for Double-hull Oil Tankers (CSR-OT). By combining collapse strength assessment procedures, thickness 
measurements and mechanical properties degradation equations, reduction of safety margin of main deck structure of oil tankers is obtained. Finally, discussion and corresponding conclusions are provided.

\section{DESCRIPTION OF SHIPS AND CORROSION MEASUREMENTS}

The paper describes corrosion wastage of two oil tankers with single-hull structure built in eighties. One ship has high tensile steel in bottom and deck areas and mild steel in neutral axis area including longitudinal bulkheads (ship no. 1), while the whole cargo area is made of mild steel for another ship (ship no. 2). Main particulars of ships are given in Table 1.

Cross section of ships is divided by two longitudinal bulkheads in three tank spaces. Central tanks along cargo hold areas are cargo oil tanks, while wing tanks can serve as ballast or cargo oil tanks, see Figure 1.

Table 1. Main characteristic of two single-hull tankers.

\begin{tabular}{lll}
\hline & Ship 1 & Ship 2 \\
\hline Length & $237 \mathrm{~m}$ & $235 \mathrm{~m}$ \\
Breadth & $42 \mathrm{~m}$ & $48 \mathrm{~m}$ \\
Depth & $20.5 \mathrm{~m}$ & $19 \mathrm{~m}$ \\
Draught & $13 \mathrm{~m}$ & $13 \mathrm{~m}$ \\
Deadweight & $78000 \mathrm{dwt}$ & $80000 \mathrm{dwt}$
\end{tabular}

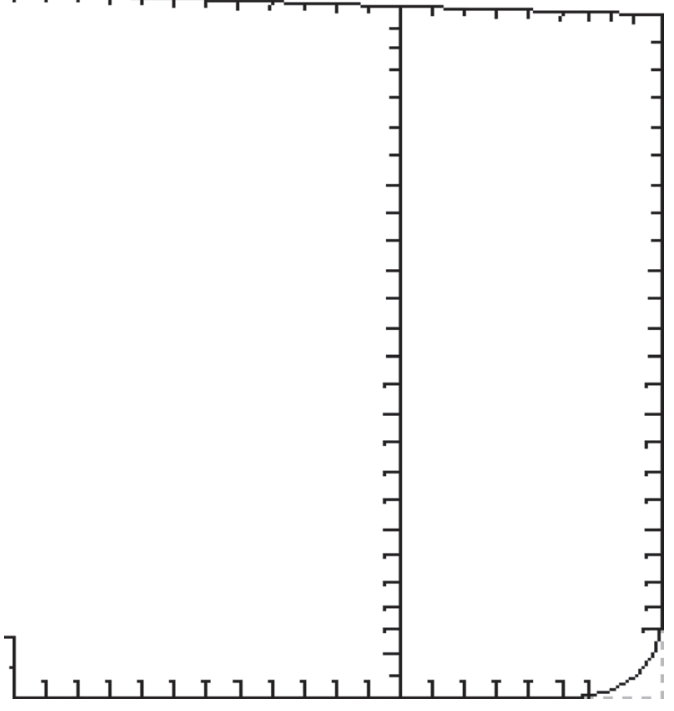

Figure 1. Midship section of single-hull oil tankers.
The measurement of the local corrosion wastage is performed separately for plates and longitudinals of the main deck in ballast and cargo tanks. The corrosion wastage is measured after 10,15 and 20 years' service life. 2135 measurements are used for ship no. 1, while 2353 for ship no. 2. Results of measurements are presented in details by Jurišić et al. (2014).

Measured mean and extreme corrosion wastage are presented in Tables $2-5$. The extreme corrosion wastage in the present paper represents the corrosion wastage having $5 \%$ probability of exceedance. To estimate extreme corrosion wastage, probability distribution of corrosion wastage is fitted to the each data set measured at

Table 2. Measured mean corrosion wastage for ship no. $1, \mathrm{~mm}$.

\begin{tabular}{lllll}
\hline Element & Area & 10 years & 15 years & 20 years \\
\hline Plates & Cargo & 0.41 & 0.72 & 1.62 \\
& Ballast & 0.25 & 0.44 & 0.92 \\
Long. & Cargo & 0.47 & 1.24 & 1.65 \\
& Ballast & 0.22 & 0.52 & 0.69 \\
\hline
\end{tabular}

Table 3. Measured extreme corrosion wastage for ship no. $1, \mathrm{~mm}$.

\begin{tabular}{lllll}
\hline Element & Area & 10 years & 15 years & 20 years \\
\hline Plates & Cargo & 0.92 & 1.51 & 2.65 \\
& Ballast & 0.67 & 1.12 & 2.27 \\
Long. & Cargo & 1.28 & 2.29 & 2.85 \\
& Ballast & 0.87 & 1.56 & 1.72 \\
\hline
\end{tabular}

Table 4. Measured mean corrosion wastage for ship no. $2, \mathrm{~mm}$.

\begin{tabular}{lllll}
\hline Element & Area & 10 years & 15 years & 20 years \\
\hline Plates & Cargo & 0.36 & 0.90 & 1.76 \\
& Ballast & 0.23 & 0.44 & 0.64 \\
Long. & Cargo & 0.53 & 1.34 & 1.85 \\
& Ballast & 0.37 & 0.58 & 0.71 \\
\hline
\end{tabular}

Table 5. Measured extreme corrosion wastage for ship no. $2, \mathrm{~mm}$.

\begin{tabular}{lllll}
\hline Element & Area & 10 years & 15 years & 20 years \\
\hline Plates & Cargo & 0.91 & 1.81 & 2.78 \\
& Ballast & 0.71 & 1.25 & 1.93 \\
Long. & Cargo & 1.97 & 3.42 & 3.97 \\
& Ballast & 0.98 & 1.41 & 1.92 \\
\hline
\end{tabular}


year $t$ of the ship life. The Weibull distribution is frequently used for representing the corrosion wastage at certain ship age (Parunov et al. 2008, Guo et al. 2008). When parameters of Weibull distribution are known, extreme corrosion corresponding to any probability level may readily be estimated.

It is interesting to notice that the corrosion wastage in cargo tanks is larger than in ballast tanks, while deck longitudinals in cargo tanks experienced the largest corrosion wastage of all ship structural components analysed.

\section{MECHANICAL PROPERTIES DEGRADATION}

The analyses of mechanical properties degradation is based on small scale corroded specimens, which were firstly corroded and then tested under uniaxial tensile load. The specimens were cut from a box girder that was initially corroded in real sea water conditions. Mechanical properties of specimens, namely modulus of elasticity, yield stress, tensile strength, resilience, fracture toughness and total uniform elongation are analysed and regression equations are derived as a function of the corrosion degree of degradation (Garbatov et al. 2014). In the present study, only modulus of elasticity and yield strength are used.

The degree of degradation, $D$ used to measure the corrosion severity, is defined as:

$$
D=\frac{V_{C}-V_{O}}{V_{O}} \cdot 100 \%
$$

where $V o$ is the intact plate volume and $V c$ denotes the corroded volume. In practice, intact and corroded volumes may be replaced by intact and average corroded thickness of structural elements respectively.

The modulus of elasticity $E$, also known as Young's modulus, has been evaluated based on the experimental results as:

$$
E(D)=-1.0349 D+206, \mathrm{GPa}
$$

The yield stress $\sigma_{y}$ results fit to a quadratic regression curve as:

$$
\sigma_{y}(D)=-0.0229 D^{2}+0.5551 D+235, \mathrm{GPa}
$$

Equation (3) is valid for mild steel, while for high tensile steel, the same ratio between intact yield strength and corroded yield strength is used for the same degree of degradation as for the mild steel.

\section{COLLAPSE STRENGTH OF \\ UNIAXIALLY LOADED PLATES AND STIFFENED PANELS}

For the collapse strength of uniaxially loaded plates, Frankland's equation is used (CSR, 2006):

$\frac{\sigma_{u}}{\sigma_{y}}=\left(\frac{2.25}{\beta_{E}}-\frac{1.25}{\beta_{E}^{2}}\right)$ for $\beta_{E} \geq 1.25$

$\sigma_{u i}=\sigma_{y}$ for $\beta_{E}<1.25$

$\beta_{E}=\frac{b}{t_{p l}} \sqrt{\frac{\sigma_{y}}{E}}$

In the above equation, $\sigma$ represents the yield stress of the plate, $\sigma_{u}$ is the ultimate collapse strength of the plate, $\beta_{E}$ is the plate slenderness, $b$ is the plate breadth, $t_{p l}$ is the plate thickness while $E$ the modulus of elasticity. It is easy to observe that the main aging effect, reduction of the plate thickness, increases plate slenderness, while degradation of mechanical properties has opposing effect. Reduction of yield strength reduces while reduction of modulus of elasticity increases plate slenderness.

For the collapse strength of stiffened panels, the procedure proposed in CSR is used. It should be clarified that CSR ultimate compressive strength is the lowest of three different buckling modes: beam column flexural buckling, stiffener torsional buckling and local buckling of the stiffener web. CSR formulae used in the present paper are those specified in CSR, APPENDIX A, Chapter 2, Section 3. More details of the procedure employed, including comparison of CSR procedure with non-linear FE method is provided by Ćorak et al. (2010).

Geometric properties of plates and stiffened panels used in the analysis are presented in Table 6. Stiffeners used for deck structure of ship no. 1 are $\mathrm{T}$ profiles, while flat bar stiffeners are used in ship no. 2.

Table 6. Geometry characteristic of stiffened panels in deck area.

\begin{tabular}{lll}
\hline & Ship 1 & Ship 2 \\
\hline Length of plate & $4600 \mathrm{~mm}$ & $4000 \mathrm{~mm}$ \\
Breadth of plate & $800 \mathrm{~mm}$ & $800 \mathrm{~mm}$ \\
Thickness of plate & $17 \mathrm{~mm}$ & $15 \mathrm{~mm}$ \\
Stiff. web height & $300 \mathrm{~mm}$ & $300 \mathrm{~mm}$ \\
Stiff. web th. & $11.5 \mathrm{~mm}$ & $28 \mathrm{~mm}$ \\
Stiff. flange breadth & $125 \mathrm{~mm}$ & $0 \mathrm{~mm}$ \\
Stiff. flange th. & $19 \mathrm{~mm}$ & $0 \mathrm{~mm}$ \\
Material (Steel) & AH32 & Mild steel (GR.A)
\end{tabular}




\section{RESULTS OF THE ANALYSIS}

The analysis of ultimate strength degradation of deck structure is performed in a way that, in addition to the thickness reduction because of the corrosion, reduced modulus of elasticity and yield stress are employed as well. That represent difference with respect to previous such analyses where only thickness reduction is employed (Guo et al. 2008).

Besides thickness reduction of local structural elements, corrosion causes also global reduction of the ship cross sectional properties, the most important one being the Hull Girder Section Modulus (HGSM). The clear consequence of the reduction of the HGSM is that global hull girder stresses are increasing. Therefore, structural capacity of the main deck decreases with time, while longitudinal hull girder stresses increases.

The assessment of the HGSM loss is performed based on the following procedure. Firstly, the as-built HGSM is calculated. Then, thickness of structural elements (plates and longitudinals) contributing to the longitudinal strength are modified according to the results of thickness measurements after 10, 15 and 20 years. Reduction of HGSM was calculated for the transverse sections with combination of central tanks as cargo oil tanks and wing tanks as ballast tanks (Jurišić et al. 2011).

The HGSM loss is the ratio of the as-gauged HGSM over the as built:

$$
\begin{gathered}
R(t)=1-\operatorname{HGSM}(\text { as-gauged at year } t) \\
/(\operatorname{HGSM}(\text { as-built })
\end{gathered}
$$

Results for measured $R(t)$ for two ships after 10 , 15 and 20 years are presented in the Table 7.

Results of the analysis of the safety margin are presented in Figures 2-5 for ultimate compressive strength of unstiffened plates while in Figure 6-9 for ultimate compressive strength of stiffened plates. Contribution of the present study is that reduction of mechanical properties is taken into account in the safety margin analysis in addition to the effects of thickness diminution because of the corrosion wastage. It should be mentioned that in Figures 2-9 some abbreviations are used because of the clarity of presentation. Thus "plate strength" means ultimate compressive strength of uniaxially loaded unstiffened plate, while "panel

Table 7. Measured $R(t)$ for two ships.

\begin{tabular}{lll}
\hline Year & $R(t)$-Ship 1 & $R(t)$-Ship 2 \\
\hline 10 & 0.0151 & 0.0145 \\
15 & 0.0225 & 0.0290 \\
20 & 0.0410 & 0.0470
\end{tabular}

strength" means ultimate compressive strength of uniaxially loaded stiffened panel (combination of stiffener and associated plating). It should also be clarified that unstiffened plate is the main deck plating bounded by longitudinal stiffeners and transverse deck girders on long and short edges respectively. In all cases plates and stiffened panels are loaded on short edges.

Upper curves in Figures 2-9 represent reduction of the ultimate longitudinal strength of plates and stiffened panels because of the aging effects. Solid upper lines represent ultimate compressive strength including only the effect of the thickness reduction

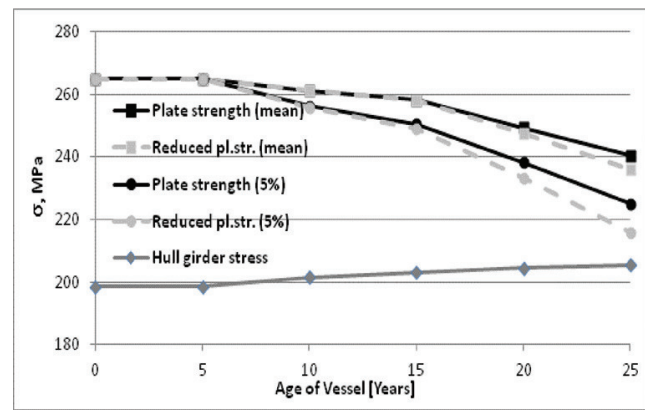

Figure 2. Results for Ship No. 1 plates in cargo oil tanks.

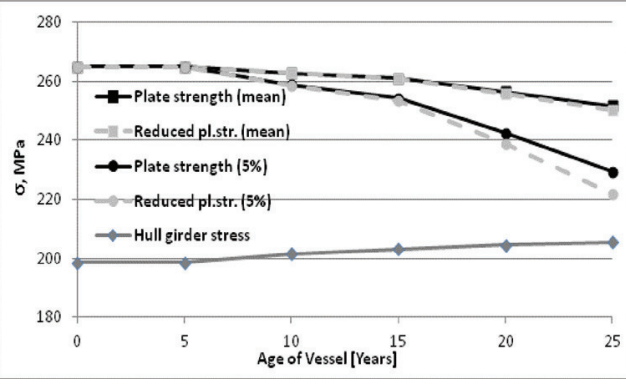

Figure 3. Results for Ship No. 1 plates in ballast tanks.

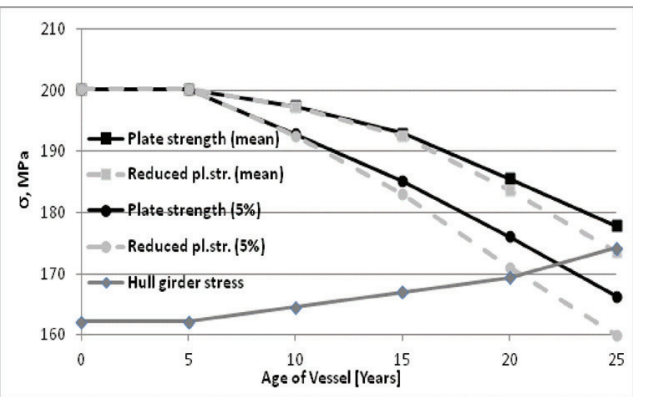

Figure 4. Results for Ship No. 2 plates in cargo oil tanks. 


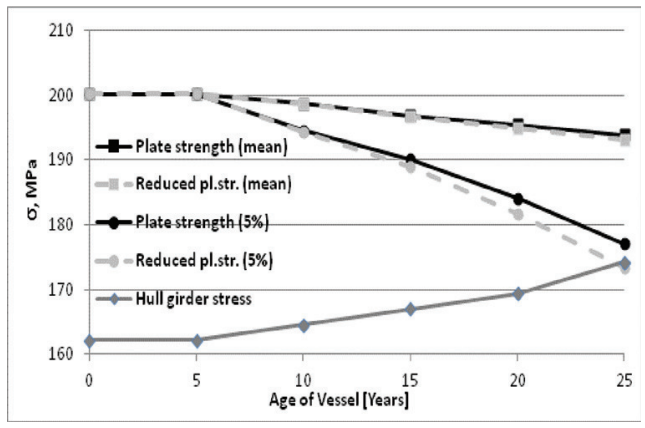

Figure 5. Results for Ship No. 2 plates in ballast tanks.

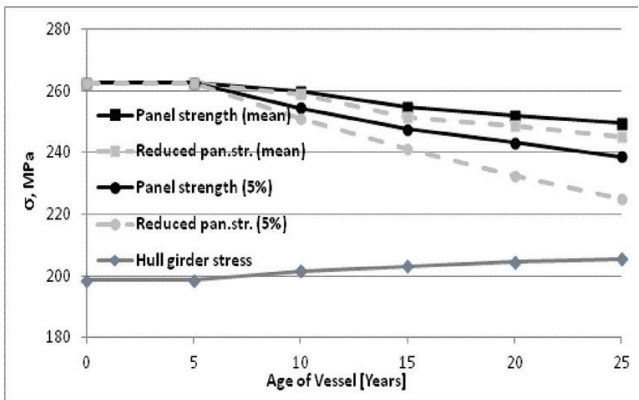

Figure 6. Results for Ship No.1stiffened panels in cargo oil tanks.

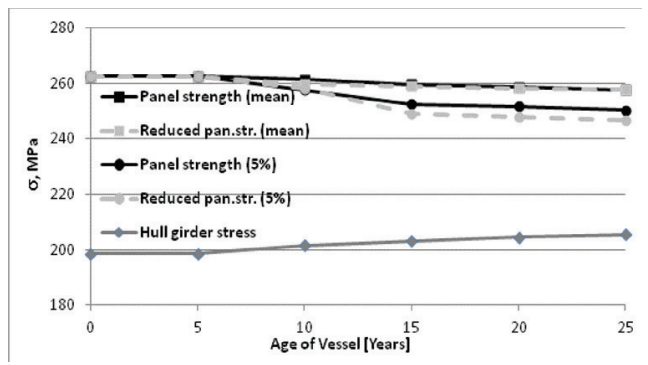

Figure 7. Results for Ship No.1stiffened panels in ballast tanks.

because of corrosion wastage, while dashed lines incorporate also effect of the reduction of mechanical properties. Two sets of results, for mean and extreme thickness reductions are presented. Extreme thickness reduction represents corrosion wastage corresponding to $5 \%$ worst plates or stiffened panels, as described in Section 2.

As may be seen in Figures 2-9, there is no reduction in ultimate compressive strength neither increase of hull girder stresses in first five years of ships in service. However, after 10 years, corrosion

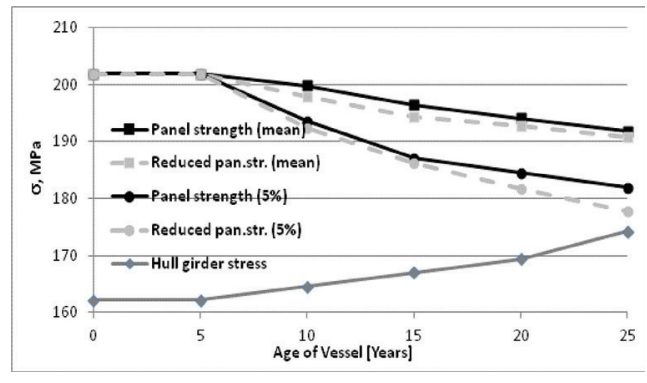

Figure 8. Results for Ship No.2 stiffened panels in cargo oil tanks.

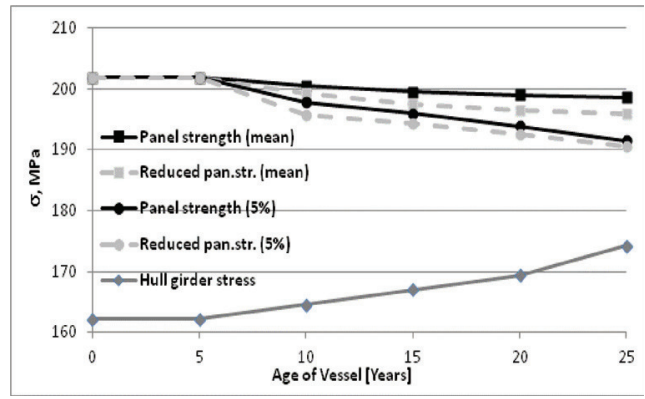

Figure 9. Results for Ship No.2 stiffened panels in ballast tanks.

losses cause moderate decrease in the ultimate strength and increase of hull-girder stresses. Difference between hull girder stresses and ultimate compressive strength represents safety margin, which is clearly decreasing with ship aging. Guo et al. (2008) proposed to use such curves to determine optimal time for inspection, which is the time when curve of hull girder stresses crosses the curve of ultimate compressive strength.

It should be noted that, although measurements are available for time up to 20 years, corrosion reduction is extended up to 25 years. For that purpose, corrosion prediction curves described by Jurišić et al. (2011) are used.

It may be seen in Figure 4 that $5 \%$ of the deck plates in cargo tanks will have inadequate ultimate compressive strength after 20 years for ship 2 . Therefore, if ship will continue her service, it would be important to perform detailed inspection of deck plates after 20 years. There is a quite obvious reduction of the plate ultimate compressive strength caused by the loss of mechanical properties of corroded steel. In all other cases, deck structure has adequate ultimate compressive strength up to designed service life of 20 years, even if the reduction of mechanical properties is taken into account. 
It may also be observed in Figures 2-9 that ultimate compressive strength of the stiffened panels is much higher compared to the ultimate strength of deck plates. That indicates appropriate and redundant structural design of deck structure as unstiffened plate would always fail before stiffened panels.

\section{DISCUSSION}

Some further clarifications of results presented in Figures 2-9 are necessary. It should be mentioned that curves denoted as "mean" are in fact valid for plate (or stiffened panel) with average corrosion wastage along whole cargo hold area. On the other side, curves denoted as " $5 \%$ " refer to the hypothetical plate (or stiffened panel) with corrosion wastage having $5 \%$ probability of being exceeded along whole cargo hold area. In other words, it is expected to find $5 \%$ of plates with lower thickness, i.e. to measure higher corrosion wastage on $5 \%$ of all main deck plates.

To avoid confusion, it is also to be clarified that results in Figure 2-9 are obtained by changing thickness and material properties $\left(E\right.$ and $\left.\sigma_{v}\right)$ in formula for ultimate compressive strength of plates and stiffened panels. While CSR stipulates that material properties are constant and that only thickness of structural elements is changing with time.

It also deserves to mention that, as the structure degrades with time, a different lowest buckling mode may occur, which is not only governed by the average residual thickness, but also by the pits distribution and local material properties. That could be taken into account by the non-linear finite element method using very fine mesh.

There is a need for more research in this field, in particular by using non-linear finite element method. In such case, other degradation effects, as reduction of tensile strength, uniform elongation and energy absorption of corroded shipbuilding steels may be taken into account. All these effects are reported by Garbatov et al. (2014) but could not be captured in simplified, rule-based analysis presented herein. Also, it would be of interest to analyse impact of degradation of mechanical properties on ultimate longitudinal hull-girder strength, as shown on the example of the model of the corroded girder by Saad-Eldeen et al. (2012).

\section{CONCLUSION}

The consequence of degradation of mechanical properties on collapse strength of uniaxially loaded plates and stiffened panels of main deck of oil tankers is investigated. Reduction of mechanical properties is caused by the complex interaction of various mechanical and chemical processes of corroded steel. It is found that, in some cases, there is obvious negative influence of this degradation which could influence structural safety. Therefore, it is advisable to consider this influence in planning of inspection of aged ships.

\section{ACKNOWLEDGEMENT}

This work has been supported in part by Croatian Science Foundation under the project 8658.

\section{REFERENCES}

Ćorak, M., Parunov, J., Teixeira, Â.P., Guedes Soares, C. 2010, Performance of the Common Structural Rules design formulations for the ultimate strength of uniaxially loaded plates and stiffened panels, Proceedings of the International Workshop "Advanced Ship Design for Pollution Prevention", Guedes Soares C., Parunov J. (edts.). Taylor \& Francis Group, London, UK.,113-120.

Garbatov Y., Guedes Soares C., Wang G. 2007. Nonlinear time dependent corrosion wastage of deck plates of ballast and cargo tanks of tankers, J. Offshore Mech. Arct. 129, 48-55.

Garbatov, Y., Guedes Soares, C., Parunov, J., Kodvanj, J. 2014, Tensile strength assessment of corroded small scale specimens. Corrosion science. 85, 296-303.

Guo et al. 2008. Time-varying ultimate strength of aging tanker deck plate considering corrosion effect. Marine Structures 21, 402-419.

Jurišić, P., Parunov, J., Žiha, K. 2011. Uncertainty in corrosion wastage prediction of oil tankers. Sustainable Maritime Transportation and Exploitation of Sea Resources. Rizzuto, E; Guedes Soares, C. (edts.). London: Taylor \& Francis. 395-400.

Jurišić, P., Parunov, J., Garbatov, Y. 2014. Comparative analysis based on two nonlinear corrosion models commonly used for prediction of structural degradation of oil tankers. Transactions of FAMENA. 38, 2; 21-30.

Parunov, J., Žiha, K. \& Mage, P. 2008. Corrosion wastage of oil tankers - A case study of an aged ship. In: Maritime Industry, Ocean Engineering and Coastal Resources. Guedes Soares \& Kolev (ed.). Taylor \& Francis Group. London. 271-276.

Saad-Eldeen, S., Garbatov, Y. \& Guedes Soares, C. 2012. Effect of Corrosion Degradation on the Ultimate Strength of Steel box Girders. Corrosion Engineering Science and Technology, 47, 272-283.

Wang, G., Boon, B., Brennan, F.P., Garbatov, Y., Ji C, Parunov, J., Rahman, T.A., Rizzo, C., Rouhan, A Shin, C.H., Yamamoto, N., 2009, Report of Committee V.6 Condition Assessment of Aging Ships and Offshore Structures, 17th International Ship and Offshore Structures Congress, Seoul, Korea.

Wang. G., Spencer, J., Elsayed T. 2003. Estimation of corrosion rates of oil tankers, in: Proceedings of the 22nd International Conference on Offshore Mechanics and Arctic Engineering, Paper OMAE 2003-37361, ASME. 